\title{
Preparation and Heat of Formation of a Magnesium Oxysulfate
}

\author{
E. S. Newman
}

(June 10, 1964)

\begin{abstract}
Magnesium oxysulfate, $3 \mathrm{Mg}(\mathrm{OH})_{2} \cdot \mathrm{MgSO}_{4} \cdot 8 \mathrm{H}_{2} \mathrm{O}$, was precipitated from metastable aqueous solutions of $\mathrm{MgO}$ in $\mathrm{MgSO}_{4}$. The compound forms in solutions containing 12 percent or more of $\mathrm{MgSO}_{4}$, and remains unchanged in solutions containing 10 percent $\mathrm{MgSO}_{4}$, but at lower concentrations is converted to $\mathrm{Mg}(\mathrm{OH})_{2}$. Magnesium hydroxide is not converted to the oxysulfate by nearly saturated $\mathrm{MgSO}_{4}$ solutions in times up to three years. The solubility of the oxysulfate is given in the form of a plot of the basicity and $\mathrm{MgSO}_{4}$ content of magnesium sulfate solutions. The heat of solution of the oxysulfate compound in $\mathrm{HCl} \cdot 26.61 \mathrm{H}_{2} \mathrm{O}\left(2.000\right.$ normal at $\left.25^{\circ} \mathrm{C}\right)$ is $68.94 \mathrm{kcal} / \mathrm{mole}$ with a standard deviation of $0.23 \mathrm{kcal} / \mathrm{mole}$ and its heat of formation from $\mathrm{Mg}(\mathrm{OH})_{2}, \mathrm{MgSO}_{4} \cdot 7 \mathrm{H}_{2} \mathrm{O}$, and liquid water is $\Delta H=2.11 \mathrm{kcal} / \mathrm{mole}$. The corresponding heat of formation from the elements is $\triangle H_{f}^{\circ}=$ $-1537.9 \mathrm{kcal} / \mathrm{mole}$.
\end{abstract}

\section{Introduction}

Magnesium oxychloride and magnesium oxysulfate cements have long been known and used for a variety of purposes, for example as binders in flooring or in insulating materials. In 1952 Newman, Gilfrich, and We]ls [1], ${ }^{1}$ and in 1955 Newman [2], published the results of thermochemical studies of the system $\mathrm{MgO}-\mathrm{MgCl}_{2}-\mathrm{H}_{2} \mathrm{O}$ at $25^{\circ} \mathrm{C}$. The present paper presents a similar study of the system $\mathrm{MgO}-\mathrm{MgSO}_{4}-\mathrm{H}_{2} \mathrm{O}$ at $25^{\circ} \mathrm{C}$.

In 1957 Demediuk and Cole [3] reviewed the previous work on the system $\mathrm{MgO}-\mathrm{MgSO}_{4}-\mathrm{H}_{2} \mathrm{O}$. In addition, they studied the reactions occurring in the system at $\mathrm{MgSO}_{4}$ concentrations up to saturation and at temperatures from 30 to $120^{\circ} \mathrm{C}$. Four oxysulfates, $5 \mathrm{Mg}(\mathrm{OH})_{2} \cdot \mathrm{MgSO}_{4} \cdot 3$ or $2 \mathrm{H}_{2} \mathrm{O}, 3 \mathrm{Mg}(\mathrm{OH})_{2}$. $\mathrm{MgSO}_{4} \cdot 8 \mathrm{H}_{2} \mathrm{O}, \quad \mathrm{Mg}(\mathrm{OH})_{2} \cdot \mathrm{MgSO}_{4} \cdot 5 \mathrm{H}_{2} \mathrm{O}$, and $\mathrm{Mg}$ $(\mathrm{OH})_{2} \cdot 2 \mathrm{MgSO}_{4} \cdot 3 \mathrm{H}_{2} \mathrm{O}$ were found, and a diagram was presented showing the conditions of stability of each. Only $3 \mathrm{Mg}(\mathrm{OH})_{2} \cdot \mathrm{MgSO}_{4} \cdot 8 \mathrm{H}_{2} \mathrm{O}$, hereafter referred to as the $3: 1: 8$ compound, was found at temperatures below about $35{ }^{\circ} \mathrm{C}$. X-ray powder diffraction patterns of each of the compounds were given.

Recently Adomaviciute and coworkers [4] reported the formula $3 \mathrm{Mg}(\mathrm{OH})_{2} \cdot 2 \mathrm{MgSO}_{4} \cdot 5 \mathrm{H}_{2} \mathrm{O}$ for the only oxysulfate formed at $20 \pm 2{ }^{\circ} \mathrm{C}$. These workers gave x-ray patterns also and differential thermal analyses (D'TA's), as well as curves showing the solubility of the compound (expressed as grams of titratable $\mathrm{MgO}$ per liter) in magnesium sulfate solutions of various concentrations. They found $\mathrm{Mg}(\mathrm{OH})_{2}$ in hardened magnesian cement and, from

${ }^{1}$ Figures in brackets indicate.the literature references at the end of this paper.
X-ray and DTA data, suggested the possibility that the formation of oxysulfate occurs in cements only above a $\mathrm{MgSO}_{4} / \mathrm{MgO}$ ratio of 0.6 .

No thermochemical data for the oxysulfates have been found in the literature. In the present work, only the $3: 1: 8$ compound was found at room temperature, and this paper is concerned with its preparation and the determination of its heat of formation. The heat of reaction of $\mathrm{Mg}(\mathrm{OH})_{2}, \mathrm{MgSO}_{4}$. $7 \mathrm{H}_{2} \mathrm{O}$, and $\mathrm{H}_{2} \mathrm{O}$ to form the compound was determined from the heats of solution or dilution of these reactants and of the compound in $\mathrm{HCl} \cdot 26.61 \mathrm{H}_{2} \mathrm{O}$ $\left(2.000 N\right.$ at $\left.25^{\circ} \mathrm{C}\right)$, and the heat of formation was calculated from this heat of reaction and heats of formation taken from the literature [5].

\section{Materials, Apparatus, and Procedure}

\subsection{Formation of the 3:1:8 Compound}

The compound was prepared by precipitation from metastable solutions of $\mathrm{MgO}$ in concentrated solutions of $\mathrm{MgSO}_{4}$, or by reaction of the latter with solid $\mathrm{MgO}$. Concentrated aqueous solutions were prepared from distilled water and $\mathrm{MgSO}_{4} \cdot 7 \mathrm{H}_{2} \mathrm{O}$ of reagent quality. In some cases the solutions were boiled to remove $\mathrm{CO}_{2}$ and cooled, protected by a $\mathrm{CO}_{2}$ absorption tube, but this procedure was found unnecessary and discontinued. Generally 4 liters of nearly saturated solution was used. Clear metastable solutions of $\mathrm{MgO}$ were prepared by shaking the $\mathrm{MgSO}_{4}$ solutions with $30 \mathrm{~g}$ of reagent-grade $\mathrm{MgO}$ freshly heated at $500{ }^{\circ} \mathrm{C}$. After about $2 \mathrm{hr}$ at room temperature the solutions were filtered and allowed to stand. Precipitation of the $3: 1: 8$ compound began in a few hours and continued slowly for 10 days or more. These concentrated, rather viscous solutions 
of $\mathrm{MgSO}_{4}$ were slow and difficult to filter and usually retained a few milligrams of material as a hazy suspension. Consequently, and also in order to encourage the formation of larger crystals, less $\mathrm{MgO}$ was used (usually $4 \mathrm{~g}$ and occasionally as little as $1.5 \mathrm{~g}$ ), filtration was omitted, the solution was sometimes seeded, and the suspension was stirred continuously with a magnetic stirrer for periods up to two weeks. The precipitate, which in every case gave the x-ray pattern of the $3: 1: 8$ compound, was recovered by filtration, suspended by stirring in methanol, refiltered and washed with more methanol, and dried at room temperature at about $20 \mathrm{~mm} \mathrm{Hg}$ pressure in vacuum desiccators over saturated $\mathrm{MgCl}_{2} \cdot 6 \mathrm{H}_{2} \mathrm{O}$ or $\mathrm{MgSO}_{4} \cdot 7 \mathrm{H}_{2} \mathrm{O}$ solution. The former solution maintains air at a relative humidity of 33 percent; the humidity over the latter solution is much higher.

Reagent-quality $\mathrm{MgSO}_{4} \cdot 7 \mathrm{H}_{2} \mathrm{O}$ was recrystallized, washed briefly with methanol, crushed to pass a No. 16 sieve, and stored in 1-g quantities in weighing bottles in partial vacuum over saturated $\mathrm{MgSO}_{4} \cdot 7 \mathrm{H}_{2} \mathrm{O}$ solution. When the samples reached constant weight, their heats of solution were determined in $2.000 \mathrm{~N} \mathrm{HCl}$.

\subsection{Determination of Solubility}

In order to obtain information about the solubility and stability of the $3: 1: 8$ compound in $\mathrm{MgSO}_{4}$ solutions at $25{ }^{\circ} \mathrm{C}$, solubility equilibrium was sought from both super- and under-saturation. Several groups of three series of solutions of $\mathrm{MgSO}_{4}$ of differing concentrations were prepared and kept in 1-liter polyethylene bottles as: A, clear unstable solutions of $\mathrm{MgO} ; \mathrm{B}$, suspensions of $2 \mathrm{~g}$ of $\mathrm{Mg}(\mathrm{OH})_{2}$; and $\mathrm{C}$, suspensions of $3: 1: 8$ oxysulfate. The $\mathrm{A}$ series was intended to approach equilibrium from supersaturation, and the $\mathrm{B}$ and $\mathrm{C}$ series, with originally zero concentration of titratable $\mathrm{MgO}$, to approach from under-saturation. These bottles were shaken by hand periodically, and the tests were continued for several years. Later, the three series were prepared and kept in continuous gentle agitation for as long as two years on a 20 -in. wheel rotating at about $15 \mathrm{rpm}$. From time to time the bottles were removed from the wheel and allowed to stand quiescent overnight. Samples of the clear supernatant liquid were taken for titration with standard $\mathrm{HCl}$ solution and phenolphthalein indicator, and the solid phases present were examined under a microscope and by x-ray patterns. The basicity obtained by titration was calculated and reported as grams of $\mathrm{MgO}$ per liter. When it became evident that little further change in basicity was likely to occur, the solid was recovered by filtration, washed with methanol, and dried at 33 percent rh. X-ray patterns and analysis of some of these precipitates were obtained.

\subsection{Analyses of Precipitates}

In the beginning, analyses were performed by standard methods [6,7], $\mathrm{SO}_{3}$ being determined by precipitating and weighing as $\mathrm{BaSO}_{4}$, and $\mathrm{MgO}$ being determined gravimetrically by the pyrophosphate method. It was found that the $\mathrm{CO}_{2}, \mathrm{SiO}_{2}$, $\mathrm{Fe}_{2} \mathrm{O}_{3}+\mathrm{Al}_{2} \mathrm{O}_{3}$ etc., and $\mathrm{CaO}$ found by the usual procedures differed little from the blank determinations and were sometimes smaller. Consequently, in the later part of the work $\mathrm{SO}_{3}$ was determined gravimetrically as before, and total $\mathrm{MgO}$ was determined as the residue when the sample was ignited to $1200{ }^{\circ} \mathrm{C}$. Tests showed that the results obtained agreed with those obtained by the pyrophosphate method and that $\mathrm{SO}_{3}$ was absent in such heated residues, confirming the work of Schnitzer, Wright, and Hoffman [8] and the results of D'TA's showing decomposition of $\mathrm{MgSO}_{4}$ at $1135{ }^{\circ} \mathrm{C}$. The water content was determined by difference. For the later samples to be used in the calorimeter, the material to be analyzed was divided into $0.5-\mathrm{g}, 1-\mathrm{g}$, and $2-\mathrm{g}$ portions in weighing bottles. These samples were equilibrated over $\mathrm{MgSO}_{4}$ or $\mathrm{MgCl}_{2}$ solutions, as described earlier, and weighted periodically. When the weights became essentially constant, the two smaller sized samples were used for analysis, and heat-of-solution determinations of the 2-g samples were begun. Periodic weighing of calorimeter samples was continued until the heat of solution was measured, and the water content at that time calculated from the weight record and the analytical results. In some cases, calorimeter samples which had been held, together with the analytical samples, over one saturated solution were transferred to the in order to change the water content. Earlier calorimeter samples were simply weighed out from a stock bottle of oxysulfate that had been equilibrated at 33 percent rh and analyzed.

\subsection{Differential Thermal Analyses}

Differential thermal analyses were performed with apparatus described elsewhere [9]. Samples of about $0.5 \mathrm{~g}$ were used, with alumina as the inert reference material, and a heating rate of about 12 $\mathrm{deg} / \mathrm{min}$ was maintained. Temperatures of about $1250{ }^{\circ} \mathrm{C}$ were reached.

\subsection{Calorimetric Measurements}

Heats of solution were obtained with an isothermaljacket platinum calorimeter described elsewhere [10]. The electrical-energy equivalent of the calorimeter was determined using instruments calibrated by the Electrical Division of the National Bureau of Standards, the time of heating being controlled by a relay activated by the standard seconds signal. Heats of solution are reported in thermochemical calories of 4.1840 absolute joules. In order to determine the effect of gross changes in the water content of the 3:1:8 oxysulfate on its heat of solution, samples were heated or otherwise dehydrated to various extents and their heats of solution determined. X-ray patterns of some of these partially dehydrated samples were obtained. 


\section{Results and Discussion}

\subsection{Formation and Solubility of the 3:1:8 Oxysulfate}

Figure 1 shows, expressed as grams of $\mathrm{MgO}$ per liter, the basicity of metastable solutions obtained by shaking $\mathrm{MgO}$ for $2 \mathrm{hr}$ with $\mathrm{MgSO}_{4}$ solutions of various strengths. Two hours is about the optimum shaking time for these conditions, since the oxysulfate begins to precipitate soon thereafter. From these solutions this compound was formed in every case if the concentration equaled or exceeded 15 percent of $\mathrm{MgSO}_{4}$. In more dilute solutions, only $\mathrm{Mg}(\mathrm{OH})_{2}$ was formed.

Figure 2 shows the change of concentration of titratable $\mathrm{MgO}$ with time for typical solutions of the $\mathrm{A}, \mathrm{B}$, and $\mathrm{C}$ series. The concentrations for the $\mathrm{A}$ series, at first rather high, decreased as the oxysulfate was precipitated. The curves given by Adomaviciute et al., [4] are quite similar. The concentration of $\mathrm{MgO}$ in the $\mathrm{B}$ and $\mathrm{C}$ series rose rapidly from zero initially to a value dependent on the $\mathrm{MgSO}_{4}$ concentration, near which it remained thereafter. These values were approximately those finally reached after longer times by the solutions of the A series.

In figure 3 are plotted the $\mathrm{MgO}$ concentrations obtained at 8 months for $\mathrm{A}, \mathrm{B}$, and $\mathrm{C}$ series kept on the wheel for the full time, plotted as a function of the $\mathrm{MgSO}_{4}$ concentration of the solution (given as percentage $\left.\mathrm{MgSO}_{4} \cdot 7 \mathrm{H}_{2} \mathrm{O}\right)$. The scatter of the points was not reduced by longer times. This figure is not a true equilibrium diagram, since $\mathrm{x}$-ray patterns showed that, for instance, $\mathrm{Mg}(\mathrm{OH})_{2}$ remained unchanged even at $\mathrm{MgSO}_{4} \cdot 7 \mathrm{H}_{2} \mathrm{O}$ concentrations up to 50 percent where the $3: 1: 8$ compound was precipitated from the A (unstable solution) series, while the oxysulfate remained unchanged in a 20 percent solution although it would not form in solutions containing less than 25 percent.

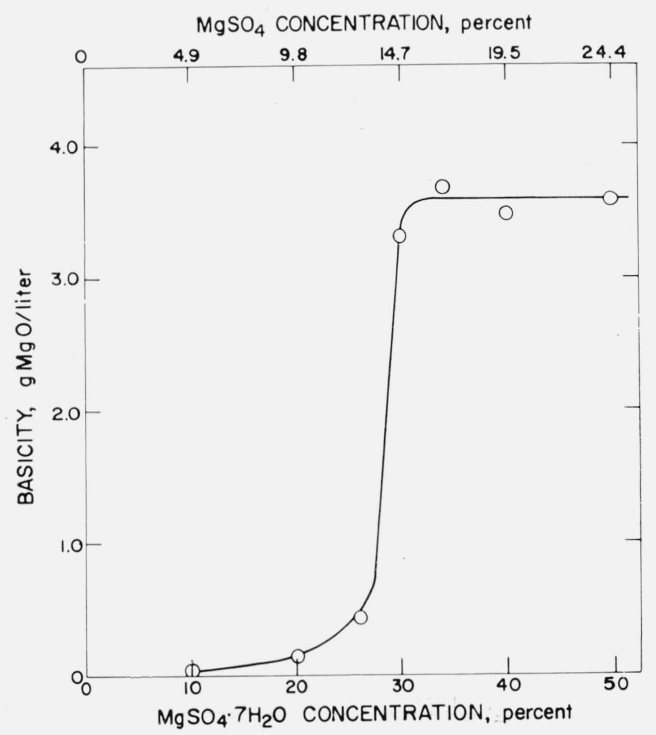

FIgURE 1. Basicity of magnesium sulfate solutions after 2.hr shaking with an excess of freshly calcined $\mathrm{MgO}$.
Also plotted in figure 3 are the 6 -month results obtained by Adomaviciute et al. [4], at $20 \pm 2{ }^{\circ} \mathrm{C}$. These values are generally somewhat lower than the results found in the present work, as might be expected because of the lower temperature. The Russian work is equivalent to the $A$ series of the present investigation. The vertical lines in figure 3 marked "A, $25^{\circ} \mathrm{C}$ " and "A, $20^{\circ} \mathrm{C}$ " represent the saturation limit of $\mathrm{MgSO}_{4} \cdot 7 \mathrm{H}_{2} \mathrm{O}$ [11]. The Russian workers remark on the presence of crystals of this compound in their more concentrated solutions.

It must be pointed out that in the present work only the $3: 1: 8$ oxysulfate and $\mathrm{Mg}(\mathrm{OH})_{2}$ were found to form, while the Russian authors report the composition of the oxysulfate as $3 \mathrm{Mg}(\mathrm{OH})_{2} \cdot 2 \mathrm{MgSO}_{4} \cdot 5 \mathrm{H}_{2} \mathrm{O}$.

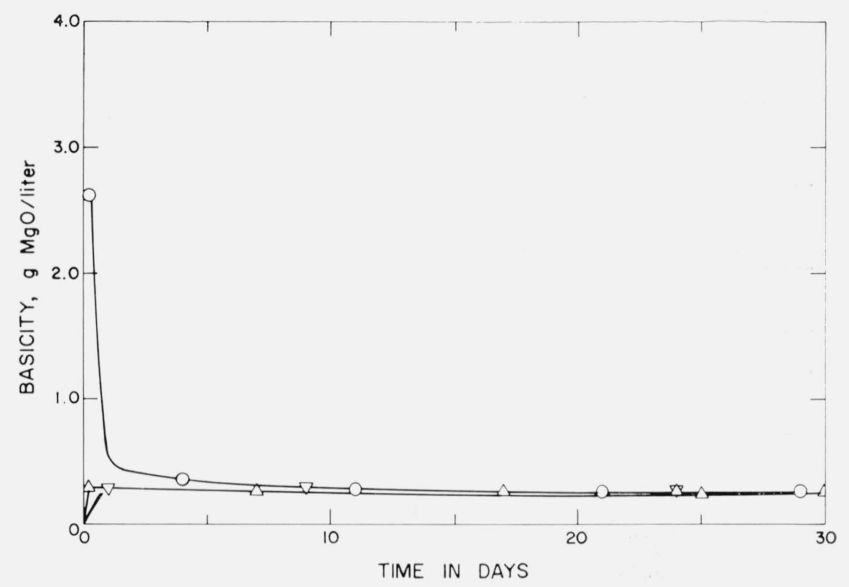

Figure 2. Basicity of magnesium sulfate solutions.

Concentration of $\mathrm{MgSO}_{4} \cdot 7 \mathrm{H}_{2} \mathrm{O}, 50$ percent.

$\odot$ A series, metastable solutions of $\mathrm{MgO}$ in $\mathrm{MgSO}_{4}$ solution. No initial solid phase

$\triangle B$ series, initial solid phase, $\mathrm{Mg}(\mathrm{OH})_{2}$

$\nabla \mathrm{C}$ series, initial solid phase, $3 \mathrm{Mg}(\mathrm{OH})_{2} \cdot \mathrm{MgSO}_{4} \cdot 8 \mathrm{H}_{2} \mathrm{O}$

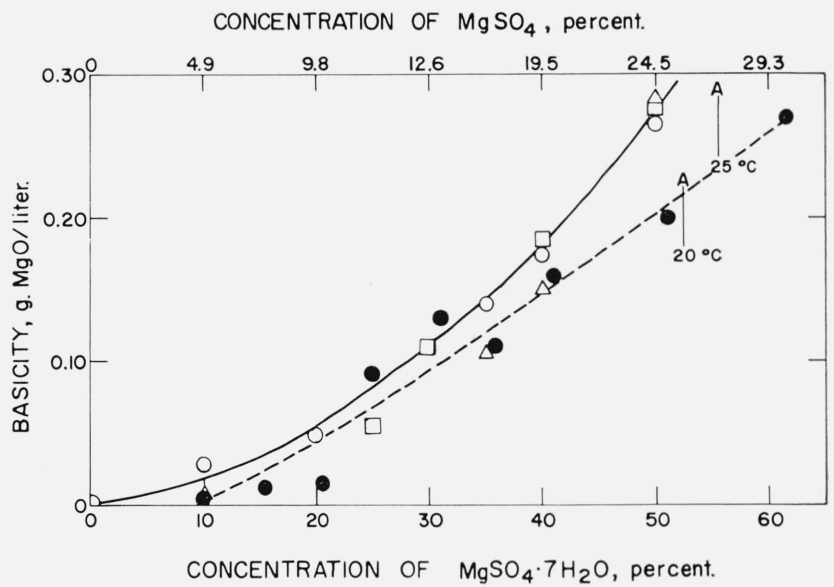

FIGURE 3. Basicity of magnesium sulfate solutions after 8months agitation.

$\square$ A series, metastable solution of $\mathrm{MgO}$ in $\mathrm{MgSO}_{4}$ aqueous solution. No initial solid phase.

$\triangle \mathrm{B}$ series, initial solid phase $\mathrm{Mg}(\mathrm{OH})_{2}$

$\triangle \mathrm{B}$ series, initial solid phase $\mathrm{Mg}(\mathrm{OH})_{2} \cdot$
$\nabla \mathrm{C}$ series, initial solid phase $\left.3 \mathrm{Mg}(\mathrm{OH})_{2} \cdot \mathrm{MgSO}_{4} \cdot 8 \mathrm{H}_{2}\right)$

Data of Adomaviciute, Yanikii, and Vektaris [4]. Lines marked $\mathrm{A}-20{ }^{\circ} \mathrm{C}$ and $\mathrm{A}-25^{\circ} \mathrm{C}$ mark the limit of solubility of $\mathrm{MgSO}_{4} \cdot 7 \mathrm{H}_{2} \mathrm{O}$. 
TABLE 1. Heats of solution of magnesium oxysulfate preparations in $\mathrm{HCl} .26 .61 \mathrm{H}_{2} \mathrm{O}$

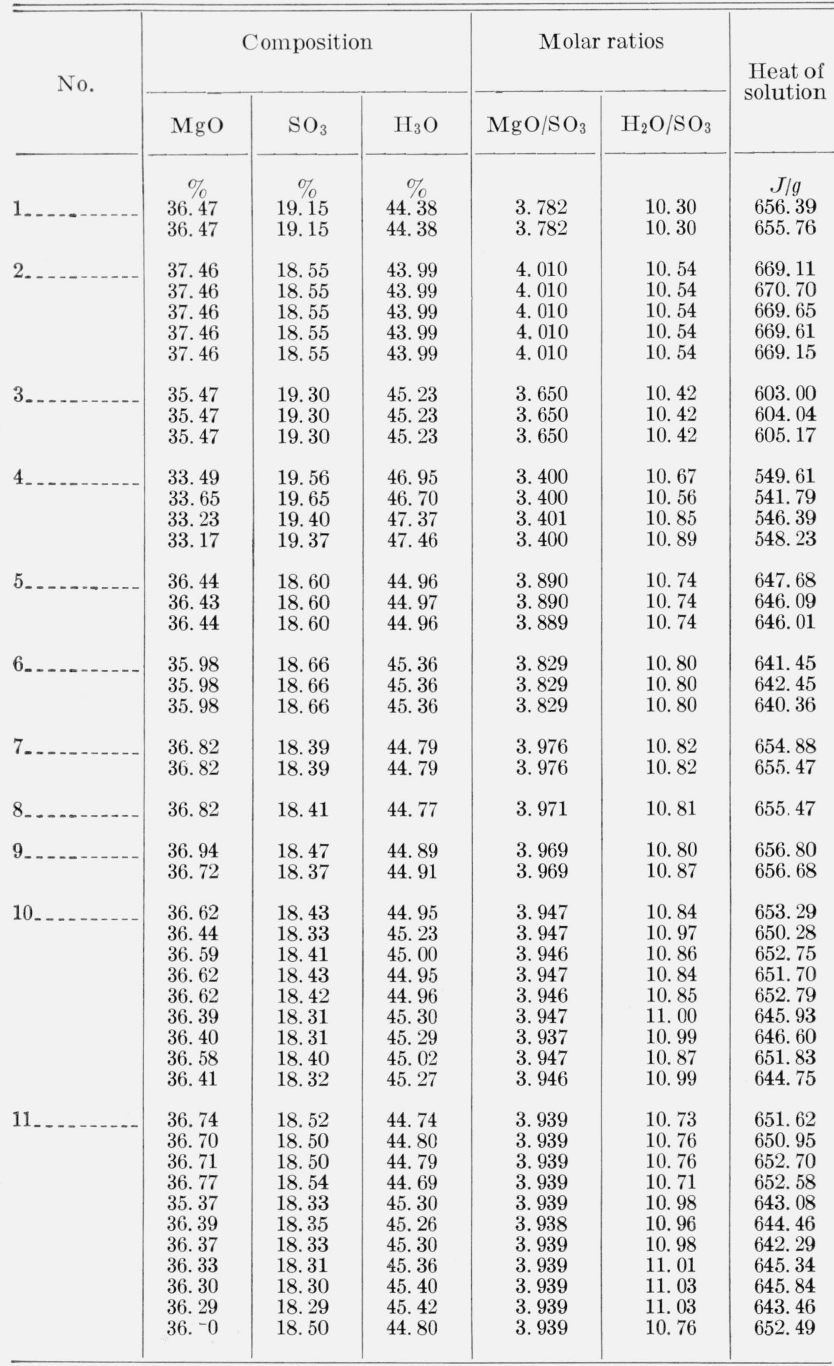

The present author believes this disagreement to be due to the differing methods of recovering the precipitated oxysulfate. Adomaviciute and coworkers first dried their preparations at a temperature not exceeding $100{ }^{\circ} \mathrm{C}$, then washed with methanol, and redried to constant weight. They comment on the incomplete removal of $\mathrm{MgSO}_{4}$ due to incomplete washing. Demediuk and Cole [3] warn that magnesium sulfate hydrates containing less than seven molecules of water are difficultly soluble in methanol and used a procedure designed to avoid their formation.

Magnesium sulfate heptahydrate loses four molecules of water when heated to $106{ }^{\circ} \mathrm{C}$ [12], and at temperatures above $68{ }^{\circ} \mathrm{C}$ the monohydrate is the stable phase in contact with solution [11]. The $3: 1: 8$ oxysulfate was found to lose four molecules of water at $105^{\circ} \mathrm{C}$. It would appear that the somewhat variable composition reported by the Russian workers might be formed by a suitable mixture of the probable components $\mathrm{MgSO}_{4} \cdot n \mathrm{H}_{2} \mathrm{O}$ and
$3 \mathrm{Mg}(\mathrm{OH})_{2} \cdot \mathrm{MgSO}_{4} \cdot n \mathrm{H}_{2} \mathrm{O}$. On the other hand, the compositions of the present author's preparations, table 1 , were not exactly $3: 1: 8$ either, $\mathrm{Mg}(\mathrm{OH})_{2}$ and $\mathrm{H}_{2} \mathrm{O}$ generally being slightly below the proportions of 3 and 8 respectively. It is believed that here, also, incompletely removed magnesium sulfate is largely responsible for the low $\mathrm{Mg}(\mathrm{OH})_{2} / \mathrm{MgSO}_{4}$ ratios. However, a $3.5 \mathrm{~g}$ sample of preparation 6 with a ratio of 2.83 (table 1) was stirred with $350 \mathrm{ml}$ of methanol, and the liquid analyzed periodically for $\mathrm{SO}_{3}$. Agitation in methanol for 5 min increased the calculated ratio of the suspended solid to 2.90; no further dissolving of magnesium sulfate from the sample occured in $6 \mathrm{hr}$. Ample methanol was present to dissolve several grams of $\mathrm{MgSO}_{4} \cdot 7 \mathrm{H}_{2} \mathrm{O}$. A small amount of magnesium sulfate may be too strongly bound to the compound for removal with methanol, the true composition may be slightly different from $3: 1: 8$, or the inevitable errors in analysis may be responsible for most of the apparent deviations. Small differences in water content are to be expected, due to variations in attaining vaporpressure equilibrium between the samples and the atmosphere in which they were kept.

\subsection{Differential Thermal Analyses}

Differential-thermal-analysis curves obtained for three oxysulfate preparations are shown in figure 4 . With the aid of oven-heating experiments and x-ray patterns obtained at various stages, the following conclusions were drawn:

Peak A at 100 to $140{ }^{\circ} \mathrm{C}$ represents the loss of four molecules of water with the formation of a material giving a different $x$-ray pattern than does the $3: 1: 8$ oxysulfate. The equivalent oven temperature is about $105{ }^{\circ} \mathrm{C}$.

Peak B at 205 to $230{ }^{\circ} \mathrm{C}$ represents the heat effect accompanying the loss of three more molecules of water and the collapse of the structure so that no lines appeared on the x-ray pattern. An oven temperature of $183{ }^{\circ} \mathrm{C}$ gave the same result.

Peak C at 430 to $460{ }^{\circ} \mathrm{C}$ represents the loss of most of the rest of the water. The x-ray pattern of $\mathrm{MgO}$ with a few lines of $\mathrm{MgSO}_{4}$ was obtained. An oven temperature of $425{ }^{\circ} \mathrm{C}$ gave the same result. This is the approximate temperature at which $\mathrm{Mg}(\mathrm{OH})_{2}$ loses its water when heated alone.

Peak D at 630 to $645{ }^{\circ} \mathrm{C}$ accompanied the loss of a small amount of water and the formation of $\mathrm{MgSO}_{4}$ according to the $\mathrm{x}$-ray pattern. It is this peak, together with x-ray data, on which Adomaviciute and coworkers based their conclusion that the oxysulfate was present in cement samples. Certain forms of magnesium carbonate also show an endothermic reaction in this range. The corresponding oven temperature was $600^{\circ} \mathrm{C}$.

Peaks E and F represent, respectively, a reversible transition of $\mathrm{MgSO}_{4}$ at 1020 to $1028^{\circ} \mathrm{C}$, similar to those found for $\mathrm{CaSO}_{4}$ and $\mathrm{BaSO}_{4}$ at higher temperatures, and the decomposition of $\mathrm{MgSO}_{4}$ to $\mathrm{MgO}$ and $\mathrm{SO}_{3}$ at 1118 to $1135{ }^{\circ} \mathrm{C}$. 


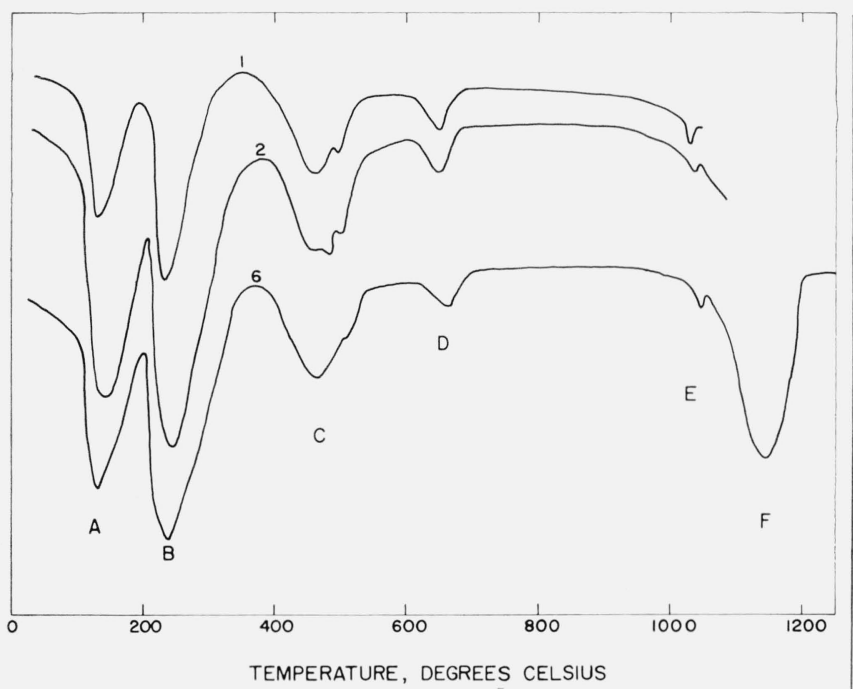

Figure 4. Differential thermal analyses of $3 \mathrm{Mg}(\mathrm{OH})_{2} \cdot \mathrm{MgSO}_{4}$. $8 \mathrm{H}_{2} \mathrm{O}$. Preparations 1,2 , and 6 , table 1 .

\subsection{Heats of Solution}

In table 1 are listed the measured heats of solutions of 11 preparations of the $3: 1: 8$ oxysulfate. Samples of $2 \mathrm{~g}$ were dissolved in $740.00 \mathrm{~g}$ of $\mathrm{HCl} \cdot 26.61 \mathrm{H}_{2} \mathrm{O}$, and in thermochemical calculations the heats of solution of approximately equivalent weights of $\mathrm{Mg}(\mathrm{OH})_{2}$ and $\mathrm{MgSO}_{4} \cdot 7 \mathrm{H}_{2} \mathrm{O}$ were used. Details of electrical calibration of the calorimeter have been given elsewhere [13]. The electrical-energy equivalent of the calorimeter was $28,450.5 \mathrm{~J} / \mathrm{ohm}$ with a standard error of $3.8 \mathrm{~J} / \mathrm{ohm}$.

Since the samples listed in table 1 do not conform exactly to the composition of the pure compound $3 \mathrm{Mg}(\mathrm{OH})_{2} \cdot \mathrm{MgSO}_{4} \cdot 8 \mathrm{H}_{2} \mathrm{O}$, a three-constant firstdegree equation relating the heat of solution to the composition of the sample was fitted to the 45 determinations of table 1 by the method of least squares on an electronic computer. The heat of solution of the compound was determined mathematically from its calculated composition and the coefficients of the equation. It has been more usual to calculate the constitution of samples in terms of the probable impurities, e. g., $3 \mathrm{Mg}(\mathrm{OH})_{2} \cdot \mathrm{MgSO}_{4} \cdot m \mathrm{H}_{2} \mathrm{O}$, $\mathrm{MgSO}_{4} \cdot n \mathrm{H}_{2} \mathrm{O}$, and $\mathrm{Mg}(\mathrm{OH})_{2}$, making assumptions of the values of $m$ and $n$, and compute a corrected heat of solution for each determination in table 1 . However, the calculated quantities would themselves be linear in terms of the composition of the samples, so it seemed equally correct to make the computation as described. A heat of solution of $656.22 \mathrm{~J} / \mathrm{g}$ (156.84 cal/g, $68.94 \mathrm{kcal} / \mathrm{mole})$ was obtained for the predicted value. The standard deviation of this predicted value [14] was $2.21 \mathrm{~J} / \mathrm{g} \quad(0.53 \mathrm{cal} / \mathrm{g}, 0.23$ $\mathrm{kcal} / \mathrm{mole})$.

That this type of computation must not be carried too far from the composition region represented by the data is demonstrated by the data shown in figure 5. In this figure are plotted the heats of solution of partially or completely dehydrated portions of

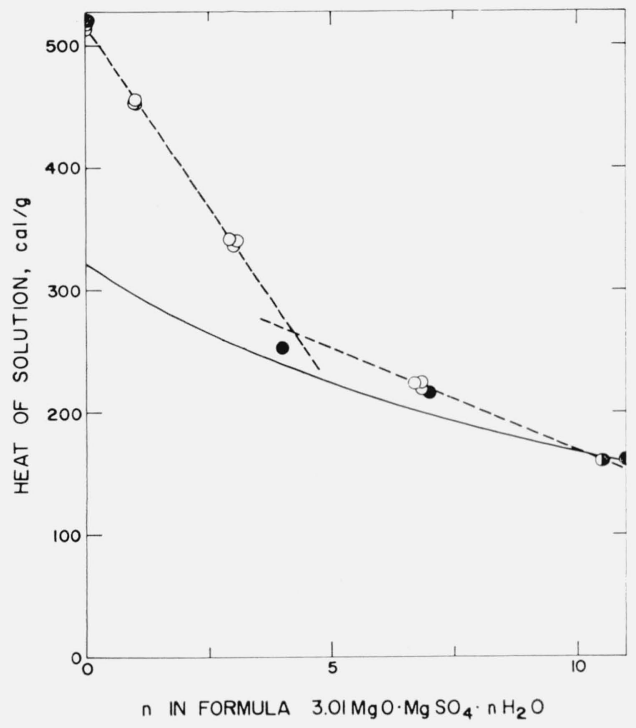

Figure 5. Heats of solution of partially dehydrated magnesium oxysulfate, $3.01 \mathrm{MgO} \cdot \mathrm{MgSO}_{4} \cdot n \mathrm{H}_{2} \mathrm{O}$, in $\mathrm{HCl} \cdot 26.61 \mathrm{H}_{2} \mathrm{O}$.

Open circles, individual experimental values.

Half-closed circle, average of five values for sample 2, table 1.

Half-closed circle, average of five values for sample 2, table 1.
Closed circles, values calculated for mixtures of indicated composition from Closed circles, values calculated for mixtures of indicated composition from
individual heats of solution $(\triangle H)$ of $\mathrm{MgO}, \mathrm{MgSO}_{4}, \mathrm{MgSO}_{4} \cdot \mathrm{H}_{2} \mathrm{O}, \mathrm{MgSO}_{4} \cdot 4 \mathrm{H}_{2} \mathrm{O}$, individual heats of solution $(\triangle \mathrm{H})$ of $\mathrm{MgO}, \mathrm{MgSO}_{4}, \mathrm{MgSO}_{4} \cdot \mathrm{H}_{2} \mathrm{O}, \mathrm{MgSO}_{4} \cdot 4 \mathrm{H}_{2} \mathrm{O}$,
$\mathrm{MgSO}_{4} \cdot 7 \mathrm{H}_{2} \mathrm{O}, \mathrm{Mg}(\mathrm{OH})_{2}$, and $\mathrm{H}_{2} \mathrm{O} ;-36.67,-15.32,-7.57,+0.70,+8.92$, $\mathrm{MgSO}_{4} \cdot 7 \mathrm{H}_{2} \mathrm{O}, \quad \mathrm{Mg}(\mathrm{OH})_{2}$, and $\mathrm{H}_{2} \mathrm{O} ;-36.67$
-26.64 , and $-0.02 \mathrm{kcal} / \mathrm{mole}$, respectively.

-26.64 , and $-0.02 \mathrm{kcal} / \mathrm{mole}$, respectively.
Solid line shows values calculated from equation fitted by least squares to 45 Solid line shows values calculated from equation fitted by least squares to 45
points from table 1 and used for computing the heat of solution $3 \mathrm{Mg}(\mathrm{OH})_{2}$. $\mathrm{MgSO}_{4} \cdot 8 \mathrm{H}_{2} \mathrm{O}$. The 11 individual experimental points shown were not used in determining the solid line.

sample 2 of table 1 as a function of $n$, the water content in moles per mole of $\mathrm{SO}_{3}$. A single straight line does not fit these data, either a curve or two straight lines intersecting at about $n=4$ giving a much better fit. This value of $n$ would correspond to the composition of a sample constituted of $3 \mathrm{Mg}(\mathrm{OH})_{2}$ and $\mathrm{MgSO}_{4} \cdot \mathrm{H}_{2} \mathrm{O}$. The $\mathrm{x}$-ray pattern of such a sample contained no lines, apparently the structure was insufficiently developed. The heats of solution of various mixtures calculated from the individual heats of solution of probable components are plotted as closed circles in figure 5. At $n=0$ and $n=7$ and 11 , there is good agreement between the experimental and calculated values. At $n=0$ the agreement is good because the sample as shown by the x-ray pattern does consist of a mixture of $\mathrm{MgO}$ and $\mathrm{MgSO}_{4}$ as assumed in calculating the heat of solution, at $n=7$ and 11 the differences are small because of the small heat of reaction of $\mathrm{Mg}(\mathrm{OH})_{2}$ and $\mathrm{MgSO}_{4} \cdot n \mathrm{H}_{2} \mathrm{O}$ to form the oxysulfate. Heats of solution calculated from the equation used to predict the heat of solution of the $3: 1: 8$ oxysulfate agree with the experimental values only in the range $n=10$ to 11 . The solid line in figure 5 represents these calculated values. The line is curved because $n$ is not linear with percentage composition. The 11 experimental points shown individually in figure 5 were not used in determining the equation.

An average value for the heat of solution of $\mathrm{MgSO}_{4} \cdot 7 \mathrm{H}_{2} \mathrm{O}$ in $\mathrm{HCl} \cdot 26.61 \mathrm{H}_{2} \mathrm{O}$ of $-151.38 \mathrm{~J} / \mathrm{g}$ with a standard error of $1.83 \mathrm{~J} / \mathrm{g}$ was obtained for six determinations. The corresponding $\Delta H$ of solution at $25{ }^{\circ} \mathrm{C}$ is $+8.92 \mathrm{kcal} /$ mole with a standard error 
of $0.11 \mathrm{kcal} / \mathrm{mole}$. These determinations were made in the standard acid charge of $740 \mathrm{~g}$ (1.43 moles) of $\mathrm{HCl} \cdot 26.61 \mathrm{H}_{2} \mathrm{O}$ without prior addition of $0.82 \mathrm{~g}$ of $\mathrm{Mg}(\mathrm{OH})_{2}$ (corresponding to a $2-\mathrm{g}$ sample of the $3: 1: 8$ oxysulfate), thereby neglecting the small heat effect due to the presence of 0.014 moles of $\mathrm{MgCl}_{2}$ in the solution.

Taylor and Wells [15] give the value $-26.64 \mathrm{kcal} /$ mole for the $\Delta \mathrm{H}$ of solution of brucite $\left(\mathrm{Mg}(\mathrm{OH})_{2}\right)$ in 2.085 molal $\mathrm{HCl}$ and discuss the dilution corrections necessary to apply to this measurement. Using their values to adjust their result to the final concentrations 0.0198 molal in $\mathrm{MgCl}_{2}$ and 2.0444 molal in $\mathrm{HCl}$ used in the present work, a $\Delta \mathrm{H}$ of solution of -26.65 $\mathrm{kcal} / \mathrm{mole}$ was obtained and used in following computations.

The partial molal heat content of water in 2.09 molal $\mathrm{HCl}[16,17]$ was used to represent the $\Delta \mathrm{H}$ of solution of water. With these data the following thermochemical equation was written:

$\begin{array}{ll}3 \mathrm{Mg}(\mathrm{OH})_{2}(\mathrm{c}, \text { brucite }) & +\mathrm{MgSO}_{4} \cdot 7 \mathrm{H}_{2} \mathrm{O}(\mathrm{c})+\mathrm{H}_{2} \mathrm{O}(\mathrm{liq}) \rightarrow \\ 3(-26.65) & +8.92\end{array}$

$3 \mathrm{Mg}(\mathrm{OH})_{2} \cdot \mathrm{MgSO}_{4} \cdot 8 \mathrm{H}_{2} \mathrm{O}(\mathrm{c})$

$$
-68.94 \quad \mathrm{kcal} / \mathrm{mole} \text {. }
$$

The heat of the indicated reaction is therefore 2.11 $\mathrm{kcal} / \mathrm{mole}$. The estimated uncertainty of this result, using the value $\pm 0.01 \mathrm{kcal}$ for brucite given by Taylor and Wells [15] and combining calibration and reaction errors as recommended by Rossini [18], is $0.57 \mathrm{kcal} / \mathrm{mole}$.

\subsection{Heat of Formation}

Using data from the literature [5] for the heats of formation of the compounds from the elements, together with the heat of reaction calculated above, the heat of formation of the $3: 1: 8$ oxysulfate from the elements is calculated to be $\Delta \dot{H}_{f}^{\circ}=-1537.9$ $\mathrm{kcal} / \mathrm{mole}$. The uncertainty of this figure in addition to the $0.57 \mathrm{kcal} / \mathrm{mole}$ indicated above depends on the uncertainty of the heats of formation used in its computation. The values $-221.00,-808.7$, and $-68.3174 \mathrm{kcal} / \mathrm{mole}$ were used for the $\Delta H_{f}^{\circ}$ of brucite, magnesium sulfate heptahydrate, and liquid water, respectively.

\section{Summary}

At $25{ }^{\circ} \mathrm{C}$ the magnesium oxysulfate compound $3 \mathrm{Mg}(\mathrm{OH})_{2} \cdot \mathrm{MgSO}_{4} \cdot 8 \mathrm{H}_{2} \mathrm{O}$ precipitates spontaneously from metastable solutions of $\mathrm{MgO}$ in aqueous $\mathrm{MgSO}_{4}$ solutions more concentrated than 12 percent or may be formed by the reaction of such solutions with solid $\mathrm{MgO}$. The oxysulfate will remain unchanged indefinitely in aqueous solutions containing 10 percent or more of $\mathrm{MgSO}_{4}$, but at lower concentrations is converted to $\mathrm{Mg}(\mathrm{OH})_{2}$. Magnesium hydroxide remains unchanged by exposures to $\mathrm{MgSO}_{4}$ solutions of any concentration up to 25 percent for periods up to three years, but dissolves slightly to give alkalinity to the solutions approximating that finally reached by dissolving $\mathrm{MgO}$ and allowing $\mathrm{Mg}(\mathrm{OH})_{2}$ or the oxysulfate compound to precipitate.

The heat of solution of the oxysulfate in $\mathrm{HCl} \cdot 26.61 \mathrm{H}_{2} \mathrm{O}\left(2.000 N\right.$ at $\left.25{ }^{\circ} \mathrm{C}\right)$ was found to be $\Delta H=-68.94 \mathrm{kcal} / \mathrm{mole}$ with a standard deviation of $0.23 \mathrm{kcal} / \mathrm{mole}$, and that of $\mathrm{MgSO}_{4} \cdot 7 \mathrm{H}_{2} \mathrm{O}$ was found to be $\Delta H=+8.92 \mathrm{kcal} /$ mole with a standard error of $0.11 \mathrm{kcal} / \mathrm{mole}$. The heat of reaction of $\mathrm{Mg}(\mathrm{OH})_{2}$ (brucite), $\mathrm{MgSO}_{4} \cdot 7 \mathrm{H}_{2} \mathrm{O}$, and liquid water to form the $3: 1: 8$ compound was found to be, using data from the literature, $\Delta H=+2.11 \mathrm{kcal} /$ mole. The corresponding heat of formation from the elements was calculated to be $\Delta H_{f}^{\circ}=-1537.9 \mathrm{kcal} / \mathrm{mole}$.

\section{References}

[1] E. S. Newman, J. B. Gilfrich, and L. S. Wells, Heat generation in the setting of magnesium oxychloride cement, J. Res. NBS, 49, No. 6, 377-83 (Dec. 1952) RP2375.

[2] E. S. Newman, A study of the system magnesium oxide-magnesium chloride-water and the heat of formation of magnesium oxychloride, J. Res. NBS, 54, No. 6, 347-55 (June 1955) RP2597.

[3] T. Demediuk and W. F. Cole, A study on magnesium oxysulfates, Australian J. Chem. 10, 287-94 (1957).

[4] B. B. Adomaviciute, J. Yanikii, and B. Vektaris, A study of the system $\mathrm{MgO}-\mathrm{MgSO}_{4}-\mathrm{H}_{2} \mathrm{O}$, Lietvos TSR Mokslu Akad. Darbai, Serija B, 2(25)219-25 (1961) (in Russian).

[5] F. D. Rossini, D. D. Wagman, W. H. Evans, S. Levine, and I. Jaffe, Selected values of chemical thermodynamic properties, NBS Circ. 500 (1952).

[6] Federal Test Method Standard No. 158, General Services Admin., Washington, D.C., May 1, 1957.

[7] ASTM Standard C25-58 Standard methods of chemical analysis of limestone, quicklime, and hydrated lime, American Soc. for Testing Materials, Philadelphia, Pa., 1958.

[8] M. Schnitzer, J. R. Wright, and I. Hoffmann. High temperature thermogravimetry of chlorides and sulphates. A study of the application to soils, Anal. Chim. Acta 26, 371-77 (1962).

[9] E. S. Newman and L. S. Wells, Effects of some added materials on dicalcium silicate. J. Res. NBS 36, 137-58 (Feb. 1946) RP1696.

[10] H. A. Berman and E. S. Newman, Heat of formation of calcium aluminate monocarbonate at $25^{\circ} \mathrm{C}$. J. Res. NBS, 65A (Phys. and Chem.), No. 3, 197-207 (MayJune 1961).

[11] International Critical Tables, Nat. Res. Council 3, 228 (McGraw-Hill Book Co., Inc., New York, N.Y., 1933).

[12] Julian Kamecki and Stanislawa Palej, Thermal and thermogravimetric analysis of magnesium sulfate heptahydrate, Roczniki Chemii 29, 691-704 (1955) (in Polish with English Summary).

[13] H. A. Berman and E. S. Newman, Heat of formation of calcium aluminate monosulfate at $25^{\circ} \mathrm{C}$, J. Res. NBS 67A (Phys. and Chem.), No. 1, 1-13 (Jan.-Feb. 1963).

[14] Experimental Statistics, Mary Gibbons Natrella, NBS Handbook 91, 6-12. (U.S. Govt. Printing Office, Washington, D.C., 1963.)

[15] K. Taylor and L. S. Wells, Studies of heat of solution of magnesium oxides and hydroxides, J. Res. NBS 21, 133-49 (Aug. 1938) RP1121.

[16] F. D. Rossini, BS J. Research 9, 679 (1932) RP499.

[17] E. S. Newman and L. S. Wells, Heats of hydration and transition of calcium sulfate, J. Res. NBS 20, 825-36 (June 1938) RP1107.

[18] F. D. Rossini, Chem. Rev. 18, 233 (1936).

(Paper 68A6-313) 